\title{
Culture and parks: incorporating cultural ecosystem services into conservation in the Tibetan region of Southwest China
}

\author{
$\underline{\mathrm{Jun} \mathrm{He}}^{1,2}$ and $\mathrm{Na} \mathrm{Guo}{ }^{1,3}$
}

\begin{abstract}
In China, along with other countries in the Global South, the number of national parks is rapidly increasing. The primary objectives of this increase are to protect global biodiversity and ecosystem services. These national parks are often established in areas rich in biodiversity and abundant in cultural diversity. Current conservation policies and practices take some considerations of cultural ecosystem services (CES). Despite these efforts, many policies and practices do not meaningfully incorporate local voices in conservation and development endeavors, but rather merely select conservation as an ambiguous goal, or focus on promoting the recreational or touristic value of a local region. Meaningfully incorporating CES into conservation measures thus presents a global challenge. Using empirically grounded case studies in Pudacuo National Park in the Tibetan region of Southwest China as an example, this research documents the processes by which CES were incorporated into both conservation efforts and the construction of this national park. We argue that examining CES should be contextualized via the exploration of cultural practices within specific locales. Incorporating CES can contribute to the success of conservation efforts, and this incorporation can also meet local spiritual and religious needs. The policy implication emerging from this research is that the current policies that guide the development of national parks in China and beyond must recognize local cultural practices and consider local cultural needs to highlight inclusivity when planning conservation projects.
\end{abstract}

Key Words: CES; cultural needs; cultural practice; ecosystem services; nature reserve; protected areas; sacred sites

\section{INTRODUCTION}

In China, the government is particularly concerned with improving the country's ecosystem services (Ouyang et al. 2016). Apart from embarking on a wide range of the world's largest ecosystem restoration programs (Bryan et al. 2018, He 2020), the government has also committed huge sums into protecting existing ecosystems via strengthening protected areas $(\mathrm{PAs})^{[1]}(\mathrm{Xu}$ et al. 2017). There has been an observed boom in the number of all types of PAs in China in the last four decades (Zinda 2012, Huang et al. 2019). The nature reserve alone, for example, has increased from 34 in 1975 to at least 2750 nature reserves in 2017 , accounting for approximately $15 \%$ of China's terrestrial land surface and covering over 1.47 million $\mathrm{km}^{2}$ (MEE 2018). Nowadays, there are a total of 12,000 protected areas in China covering $20 \%$ of China's total land surface, playing a crucial role in safeguarding global biodiversity and providing critical ecosystem services within the country and beyond (Xu et al. 2019).

Because most PAs in China are situated in poor regions inhabited by diverse ethnic groups ${ }^{[2]}$, there is increasing concern regarding the trade-offs and synergies between conservation and human well-being (Zhou and Grumbine 2011). In 2017, the Chinese government initiated a plan for establishing 10 pilot national parks built on existing PAs with the aim of not only promoting local economic development but also conserving critical ecosystem services (State Council 2017, Wang 2019, Zhang et al. 2020). Notably, these 10 pilot national parks also inclusively consider elements of cultural ecosystem services (CES). However, scholars have also raised concerns that CES have been overemphasized for tourism development in national parks (Zinda 2017, Wang 2019), while other aspects of CES, such as religion, spirituality, and ritual customs associated with ecosystems have been largely ignored. Thus, a holistic understanding of how CES interact with the outcomes of conservation is lacking.

As PAs boom in popularity in China, a growing body of literature has emerged that examines the process of PA-building. The majority of these studies have been carried out by natural scientists in the field of conservation science who focus on the contradictory relationships between local people and PAs. Ecologists, in particular, have criticized the ways in which humans interrupt environmental functions and services, including ecosystem fragmentation and the booming of cash crop in PAs ${ }^{[3]}$ (e.g., Liu et al. 2001, Zhu et al. 2004, Allendorf and Yang 2013, Ahrends et al. 2015, Chen et al. 2016, Zang et al. 2017). Others report on increased conflicts between local people and PAs owing to restrictions in resource use, such as in the collection of nontimber forest products (NTFPs; e.g., Weckerle et al. 2010, He 2018) and firewood harvesting (e.g., He et al. 2009, Woodhouse et al. 2014). Moreover, scholars now realize that there can be additional conflict when protected wildlife damage local farms and even threaten local peoples' lives while locals are left without recourse (e.g., Chen et al. 2013, Li et al. 2018). Despite the unrelenting growth of tourism in PAs, scholars are now criticizing negative impacts from tourism on both ecosystem conservation and local benefit-sharing (e.g., Yeh 2013, Zinda 2017). Although the literature calls for increased consideration of local cultures and knowledge in deciding PAs policies (e.g., Xu et al. 2006, Xu and Melick 2007), our understanding of the relationship between CES and PAs remains incomplete. Thus, there is severe underdocumentation of how CES interacting with conservation efforts can contribute to biodiversity conservation policies in PAs while simultaneously meeting local needs.

Globally, approaches to inform understandings of CES remain the subject of ongoing debate. Scholars have attempted to

\footnotetext{
${ }^{1}$ National Centre for Borderland Ethnic Studies in Southwest China, Yunnan University, ${ }^{2}$ School of Ethnology and Sociology, Yunnan University, ${ }^{3}$ Yunnan Academy of Social Sciences
} 
explicitly link ecological structures and functions with cultural values and benefits in order to enable the development of methodology in CES assessment (Daniel et al. 2012). A rich body of literature has explored culture values in CES, with a primary focus on recreational or touristic values (e.g., de Groot et al. 2010, Fish et al. 2016, Stålhammar and Pedersen 2017). Others have attempted to evaluate cultural benefits and values via monetary calculations (cf. Milcu et al. 2013, Hirons et al. 2016). Although there is increased interest in the human well-being component of CES (e.g., Bullock et al. 2018, Bryce et al. 2016), it has largely been argued that there is a lack of deep engagement with culture norms and practices in ecosystem management, such as with religion, spirituality, and taboos (Chan et al. 2012, Gould et al. 2015).

It is widely acknowledged that indigenous culture plays a crucial role in protecting nature and serving local religious and spiritual needs while also being responsible for forming values in CES (Daniel et al. 2012). Existing literature documents the ways in which CES contribute to conservation, including the establishment of cultural keystone places (e.g., Cuerrier et al. 2015, Lepofsky et al. 2017), cultural keystone species (Garibaldi and Turner 2004), and biocultural diversity (e.g., Bridgewater and Rotherham 2019). Although these efforts are commendable, a comprehensive exploration of how CES interacted with conservation remains insufficient, and in particular, there is a paucity of research originating from the Global South.

In the Global South, conservation efforts in PAs oftentimes manifest in an approach of exclusion, undermining the local rights and participation capacities of locals who have been residing in the PAs for centuries (e.g., Adams 2004, Brockington and Igoe 2006, Martin et al. 2018, Woods 2019). Although the body of literature calls for prioritizing poverty reduction and human well-being in conservation lands (Dowie 2011, Holmes et al. 2017, Fisher et al. 2020), these efforts have been debated for their questionable effectiveness in conservation and negligence of vital cultural elements. Currently, new challenges are emerging as more and more conservation policies are introduced into the Global South (for example, national park establishment, payment for ecosystem services, ecosystem restoration projects), which might influence cultural practices in association with ecosystem services (e.g., Brown and Murtha 2019, He 2021). Therefore, there is an urgent need to understand how CES interface with conservation policies as well as how the outcome of this interfacing affects conservation and CES. An accurate and culturally appropriate way of understanding the ways in which CES influence ecosystem management can significantly contribute to the formation of relevant conservation policy (Pascua et al. 2017).

Unlike existing literature, this research attempts to examine CES via local cultural practice, which is closely entwined with ecosystem services within specific locales. With a deep engagement with local cultural practice, this approach would help to understand the interaction between CES and conservation. To do so, we contextualize our research by using empirically grounded case studies in Pudacuo National Park, located in a Tibetan region of Southwest China, as an example. By examining cultural practice in agropastoralism, use of multifunctional forests and sacred waterscapes, the research aims to unearth a holistic picture of the interactive relationship between CES, conservation, and local well-being. As such, the paper examines the processes by which CES were incorporated into conservation efforts at a specific locale. We argue it would be a risk to separate ecosystem service assessment from local cultures in conservation policy because local cultures at specific locales are highly embedded with the biophysical ecosystem surrounding them, forming an interconnected network of CES. The research shows that recognizing CES can contribute to the success of conservation efforts, and incorporating CES can also meet local spiritual and religious needs. Thus, the contributions of the paper are to fill in the knowledge gap for CES valuation and understand the interface between CES and conservation. The research also informs policy makers in China and beyond regarding the twin needs of recognizing CES and considering CES when planning conservation projects.

\section{METHODOLOGY}

\section{Study area}

The research was conducted in Pudacuo National Park, also known as Potatso National Park, which is located in Shangri-La County, Diqing Tibetan Autonomous Prefecture, Yunnan Province of China (Fig. 1). The park was promoted as a pilot site for the first batch of national parks ${ }^{[4]}$ in China to explore a new model of conservation capable of fulfilling conservation and development needs (Zhou and Grumbine 2011, Wang 2019). Pudacuo National Park covers a total area of $602 \mathrm{~km}^{2}$. It features a typical alpine ecosystem that includes a primary forest ecosystem, wetlands, and alpine meadows. The government established this protected area to conserve these ecosystems, which are home to a wide range of conserved keystone species including five floras and 10 faunas classified as national firstranked protected species (PNPP 2009). Apart from state-owned land, $30 \%$ of the total area in the park is collective-owned land distributed unevenly among three administrative villages (PNPP 2009). These villages consist of different ethnic groups including Tibetan, Naxi, Yi, and others with unique local practices and traditional cultures associated with the surrounding ecosystem (Wang 2019). The planning and building of Pudacuo National Park, therefore, had significant impacts on local communities.

Fig. 1. Location of study area.

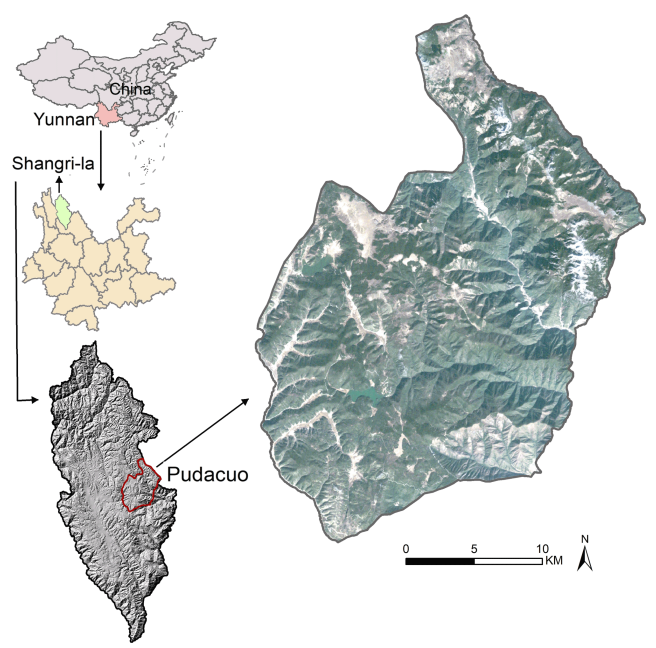


As the first pilot of national park experimentation in China, Pudacuo offers a crucial opportunity to investigate the relationship between people and PAs. Although increased ecological concerns have accompanied booming ecotourism industries (e.g., Zinda 2012, 2017, Wang 2019), the current formalization of national park system policy across the entire country provides an opportunity for local governments to adjust their operational plans and practices in order to meet the original twin goals of conserving natural and cultural landscapes. As such, the dynamic relationship between park and people attracted considerable attention from the government, NGO practitioners, and academics.

The empirical case study was carried out in Hongpo Administrative Village, which consists of 15 natural villages ${ }^{[5]}$. Among the 15, one natural village is located in Pudacuo National Park, while other village lands are only partially included in the park land. However, all villagers traditionally use resources in the park including NTFP collection, forest, pastoralism, geopiety practices, etc. There are 2373 total inhabitants in the village divided into 448 households. The village population is $99.8 \%$ Tibetan. The current net cash income per capita per year was 7100 RMB (about US\$1055) in 2017. The Tibetan villagers have been practicing Tibetan Buddhism as a traditional religion for centuries, until they built a Buddhist temple hundreds of years ago, Dabao Monastery, to meet new cultural needs.

Hongpo Village covers a total area of $198 \mathrm{~km}^{2}$, with 15,540 ha of forest and pastoral land and 374.9 ha of agricultural land. The high altitude limits the possibility for large-scale farming and high agricultural yield (average 3500 m.a.s.l.), so villagers have traditionally practiced upland agropastoralism for subsistence along with cultivating barley and potato in combination with raising yaks, cattle, and pigs. Recently, they have engaged in the market-oriented strategy of commercial mushroom collection and rape seeds cultivation. Since the establishment of Pudacuo, opportunities for direct and indirect benefits from engaging in ecotourism have become important sources of cash income for villagers.

\section{Methods}

Both authors have been engaged long-term in the region with research on indigenous people and PAs. The first author has extensive policy and pilot site experience from his involvement in the early stages of planning the national park experiment in Yunnan, starting from first working at a local NGO from 2002 to 2005 and an international NGO from 2005 to 2009, and currently continues to work in northwest Yunnan on park-related issues. The second author has been conducting $\mathrm{PhD}$ research at Pudacuo since 2017, focusing on environmental justice issues. This extensive experience had allowed the researchers to establish good rapport with the local people, which provided the crucial foundation for employing an empirically grounded approach to researching the area.

Empirically, this paper uses an in-depth case study approach to glean insights into the incorporation of CES in the national parkbuilding process. Through the ethnographic approach, we draw upon previous experiences and field data generated from three periods of intensive fieldwork, each of which had a different focus. From 2002 to 2004, the first author carried out a preliminary survey at Pudacuo, with a focus on local livelihoods along with park-building feasibility. At the time, he investigated the impacts on local natural resource management practices on the early establishment of Pudacuo National Park. Issues related to agropastoralism, harvesting non-timber forest products, indigenous knowledge, culture, and emerging opportunities for tourism development were extensively investigated. In the second period of fieldwork, the first author conducted fieldwork in August 2014 focusing on the operation and management of Pudacuo National Park as well as the extent to which indigenous people were involved with tourism development, ecosystem compensation to indigenous communities, and local cultural practices. As a follow-up study, the 2014 fieldwork additionally allowed the author to observe the effects of the park on local people and the ways in which locals engaged with Pudacuo National Park after the park had been established for a period of time. The last intensive period of fieldwork was carried out from September to October 2019 by both authors. The focus of this most recent fieldwork is to understand long-term dynamic relations between local communities and the park. Taking a longitudinal approach, this fieldwork generates insights from the process of changing national park policies in relation to local communities and their livelihoods. Finally, the fieldwork also examined local cultural dimensions as windows into understanding relations between park and CES practice.

A robust dataset was generated across these three periods of fieldwork. A variety of ethnographic methods were used, including participant observation, in-depth interviews, and focus group discussions. Participant observation allowed us to understand local practices regarding the use of natural resource and cultural norms. Participant observation is a particularly powerful tool for verifying gaps in information derived from interviews and actual observed practices. A total of 52 in-depth interviews were conducted with various stakeholders to understand the relations between local traditional practices and national park management. Interviewees included elders, women, and villagers in the communities as well as village heads in each natural village and the village head from the governing administrative village. Interviews were also conducted with local and international NGO workers involved in the planning of Pudacuo National Park, officials from both the National Park Bureau and forest departments at both prefectural and provincial level, park authorities, and forest rangers working in the park. A total of five focus group discussions were carried out for villagers, NGO workers, and forest officials regarding three general questions: (1) what were the effects of national park-building on local people; (2) how did different stakeholders negotiate national park management; and (3) what is the role of local traditional practices in conservation. The application of numerous diverse methods helped obtain a holistic understanding of local cultural practices in the park.

\section{PUDACUO NATIONAL PARK: AN OVERVIEW}

In 2007, Pudacuo National Park was declared China's first national park by the Yunnan Provincial Government. The experimental pilot program for national parks was officially launched in 2017 at the national level (Zhou and Grumbine 2011, Zinda 2012, Wang 2019). The idea of national parks was first introduced into China by The Nature Conservancy (TNC) and other NGOs in 2001, which promoted experimentation with an international national park model as an addition to the 
conventional system of nature reserves for conservation. Unlike strict nature reserves, TNC suggested following IUCN Category Two standard for parks to "protect large-scale ecological processes, along with the complement of species and ecosystems characteristic of the area, which also provide a foundation for environmentally and culturally compatible spiritual, scientific, educational, recreational and visitor opportunities" (cf. Zhou and Grumbine 2011:1316). As a potential way to promote synergies between protecting biodiversity and human livelihoods, national parks have attracted the attention of the Yunnan Provincial Government, which is now experimenting in using this new conservation model in the province (Zinda 2012).

Pudacuo National Park was built on top of a provincial-level nature reserve named Bitahai. The Bitahai Nature Reserve was established in 1984 to protect alpine and wetland ecosystems. However, at that time, lack of a clear legal framework for managing provincial-level nature reserves created a space for people to carry out economic activities throughout the nature reserve. In 1995, a local ecotourism company associated with the local Forestry Bureau began operations, while villagers living around the Bitahai Nature Reserve also started to engage in touristic activities, such as horseback-riding, hiking, and barbecuing. These ecotourism developments benefited both the local government and villagers, but there was also concern that these activities were not well regulated and might have negative impacts on the environment. Following the approval of the "Three Parallel Rivers" (Yangtz, Mekong, and Salween) in northwest Yunnan as a Natural World Heritage Site, from 2006 to 2007, the local government began to incorporate the large area surrounding the Bitahai Nature Reserve for the establishment of Pudacuo National Park, expanding the reserve from approximately 143 $\mathrm{km}^{2}$ to $602 \mathrm{~km}^{2}$ (PNPP 2009). This expansion impacted three administrative villages with 821 households who traditionally depended on natural resources within in the park (PNPP 2009) ${ }^{[6]}$. A multidisciplinary team consisting of both natural and social scientists was formed for input into park planning. This team highlighted issues of participation by local communities in park management (Zinda 2012, Wang 2019).

Administratively, the Pudacuo National Parks Management Bureau was established for park operation and management, whereas a state-own tourism company was also formed to stimulate tourism development in 2007. Incorporating the idea from TNC regarding national park creation and results from the multidisciplinary research team ${ }^{[7]}$, the local government designed four zones in Pudacuo with different functions: (1) a restricted zone comprising the core protected area $(26.2 \%$ of the total park land area); (2) an ecological zone for general conservation and ecosystem restoration (65.8\% of total park land area); (3) a recreational zone for tourist development ( $4.6 \%$ of total park land area); and (4) a traditional utilization zone in which villagers are permitted to use natural park resources $(3.4 \%$ of total park land area). This classification has not only allowed for tourism development, but also ensured that local traditional livelihood activities can be carried out in the park. Moreover, this classification sought to meet government goals for development while also implementing meaningful conservation. As a World Heritage Site and pioneering initiative, the local government aimed to set up the park for incorporating the conservation of both natural and human landscapes. In particular, the government has sought out a new conservation model for incorporating local traditions and culture for conservation.

Since its establishment, the recreational zone of Pudacuo National Park has been open for tourists. It was reported that it received 106.27 million tourists from 2007 to 2017, generating 2.24 billion RMB (about US\$35 million) in tourism revenue. These profits have benefited both the local government and local villagers and been used for investment in conservation and local livelihood development. Apart from restrictions in resource use, any tourism-related activities operated by villagers, including horse-riding, barbecuing, and renting Tibetan clothes for photos were prohibited in 2007, with the aim of consolidating authority among park management staff over the regulation of human activities and tourism operations. Park authorities enforced restrictions for regulated tourist activities and conservation targets. To subsidize the villagers' losses, the park provided two rounds of compensation for more than 800 households. The provided compensation varied based on impacts on different households. In the first round, from 2008 to 2013, park compensation to highly impacted households ${ }^{[8]}$ reached an average of 46 thousand RMB per year per household (about US\$7000), and this number doubled in the second round of evaluation (2013-2018). Apart from monetary compensation, the park also provides job opportunities to villagers, like cleaning, fire control, hotel operations, etc. These have also become additional income sources for members of local communities.

\section{PRACTICE OF CULTURAL ECOSYSTEM SERVICES IN THE PARK}

\section{Incorporation of agropastoralism into the park}

Agropastoralism as a system linking humans to the ecosystem is an important practice contained within Tibetan cultural practices. In Hongpo Village, people were allowed to continue practicing agropastoralism after the park's construction. Land tenure arrangements for agricultural land and pastureland did not change, and people were allowed to continue their livelihood practices. Moreover, community development has been touted as a priority for the park (PNPP 2009). In the agriculture sector, people continue to cultivate barley, turnips, potatoes, rape seed, and wheat. Barley and wheat are particularly important for local food and yak fodder. In addition, cultivated indigenous varieties of barley fulfill a specific spiritual use during praying. This is because a local religious tenet requires the use self-cultivated instead of purchased barley in ceremonies and rituals. Park authorities have particularly encouraged decreasing fertilizer use and maintaining wooden fencing throughout agricultural lands to limit crop damage by animals. Meanwhile, the wooden frame used for drying barley continues to be used by villagers. The integration of traditional Tibetan agricultural practices with the natural scenery has become a central attraction for tourists (Fig. 2).

Apart from agriculture, animal husbandry also plays a critical role in local Tibetan livelihoods. Locals are permitted to continue engaging in animal husbandry. Tibetans tend to employ rotationbased grazing for yaks and cattle. Local people have traditionally grazed their yaks at higher altitudes in the summertime, and these animals tend to return to the village in the fall. This practice requires a large area of grazing land, which is collectively managed 
Fig. 2. Villagers live in the park practicing agropastoralism for local livelihood and cultural needs, and also have aesthetic value for tourism.

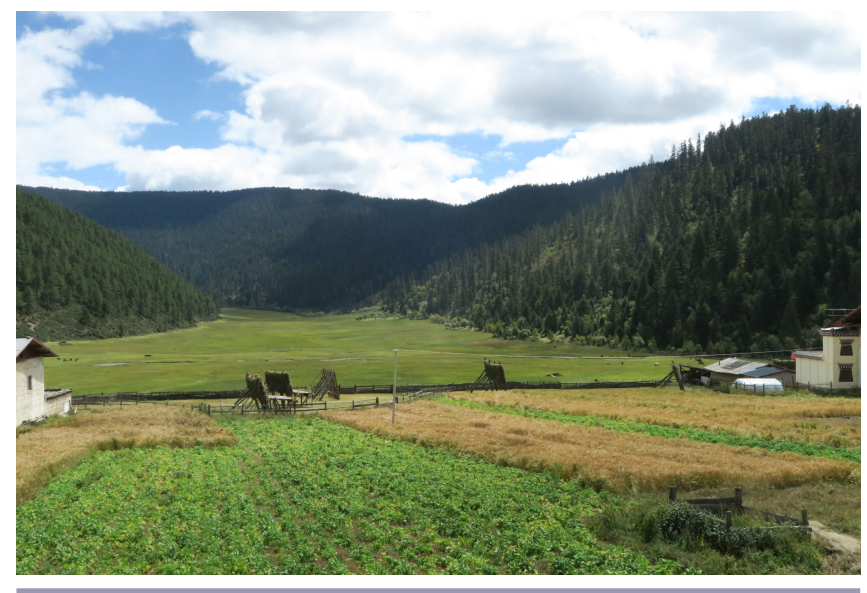

under the customary tenure arrangement in that each village has its own apportioned plots for summer and winter. Traditional rotational grazing is well adapted to the ecosystem. Indeed, the grazing process creates resplendent views, satisfying the aesthetic demands of tourists. People reside in wooden houses dotted over the mountain landscape over summer, facilitating the caretaking of yaks and making yak butter. These small wooden houses were permitted to remain after the park was established. Nonetheless, there are three restrictions for keeping this kind of house: (1) each household may have only one house with no expansions; (2) the house can only be built of wood as representative of the Tibetan tradition; and (3) indoor fires can only be used for cooking. Even with these restrictions, this arrangement was widely welcomed by local villagers:

\begin{abstract}
One wooden house is good enough. Tourists like to see our homes with our yaks. This is our tradition. We are even allowed to cut down trees to rebuild the house in case it needs repairs... It is still common now for people to raise seven to eight yaks per household, and some have up to 50 yaks if they have enough labor. It [the park] does not affect our grazing. (Interviewed in Hongpo Administrative Village, 1 October 2019)

We definitely cannot use fire outside the wooden houses, otherwise the fire will destroy the forest and park, and then nobody will benefit from the park. We even check fire use for others, like tourists and park managers. We have to live here for generations. If the forest is destroyed, how can we make a living? It is good luck that there has not been a single case of forest fire since the park was set up. (Interviewed in Hongpo Administrative Village, 30 September 2019)
\end{abstract}

As conservation efforts continue, locals have observed an increase in wild animals in the park, particularly in wild boar and deer populations. Tibetans also use these animals for the development of animal husbandry. By tradition, people graze their pigs in the summertime at high altitudes, reducing total fodder needs. All year long, local female pigs mate with wild boars, which then give birth to hybrid pigs. These hybrid pigs look different from the local black pigs and different from brown wild boars. These hybrid pigs produce a better-tasting meat with serious market potential. This practice originated approximately 10 years ago when farmers began to bring their female pigs to high altitudes during summer with their yaks to breed hybrid pig offspring. Selling this lucrative hybrid pig meat has become an important channel for supplementing local incomes. Despite this, low-altitude pig grazing is prohibited on pastureland. Park authorities claim that the digging behavior of the pigs would damage the soil and rangeland.

In sum, agropastoralism as a CES practice is not only crucial for local livelihoods, but it also meets religious and spiritual needs. Additionally, traditional agropastoral practices have aesthetic and recreational values tourists find attractive. It is thus selfevident why Pudacuo Park allows locals to maintain their agropastoralism traditions: to avoid conflict and bolster tourism efforts. Accordingly, the local people have also taken advantage of ecological benefits resulting from conservation to develop a hybrid pig variety, whose breeding can help further supplement incomes. Local agropastoralism thus contributes significantly to agrobiodiversity conservation. Although certain restrictions are imposed by park authorities, local people accept them as necessary to achieve better conservation results, which in turn further benefit local people via compensation from tourism development.

\section{Managing the multifunctionality of the forest}

Regular park functions impact forest use. Despite this, local communities continue to use forest resources for different purposes, such as timber, fuelwood, non-timber forest products, religious activities, etc. Originally, park designs seriously restricted forest use activities of local communities to meet their multifaceted needs. However, the communities have negotiated with the park manager to achieve recognition of the multifunctionality of the forest ecosystem from a local cultural perspective that can satisfy local needs.

Any felling of trees has been prohibited in order to conserve the forest ecosystem per park regulations. Enforcing this regulation presents challenges because compliance is not ubiquitous among residents in park-owned forest lands. Although many interviewed villagers raised concerns over limited forest use, it was commonly agreed that there is nonetheless a need for forest protection in order to maintain a stable ecosystem. For this, villagers have proposed a local adaptive strategy regarding timber and fuelwood use that has been welcomed by both park authority and community members. In order to address the costliest timber activity, home construction, the village proposed and enacted a new rule extending the traditional 10-year-interval for home reconstruction to every 30 years. This extension significantly reduces forest timber use. Furthermore, only one household is allowed to rebuild its home every year.

As for fuelwood, the village organizes a collective fuelwood gathering event after barley harvesting in late October. Participants need to prepare an adequate amount of fuelwood for use throughout the upcoming year. The fuelwood event lasts 15 days, with village groups gathering from their collective-owned forests in the park. The village also established the rule that only one cubic meter of fuelwood is allowed per person and only dried 
and dead trees can be cut (no felling live trees). If households have elderly or disabled residents under their care, they are permitted to cut up to $1.2-1.5$ cubic meter because these individuals may spend more time indoors, thereby necessitating more fuelwood to maintain heating. During this cutting season, the village head together with local forest rangers inspect the amount of harvested timber for each household every day. This regulation has been effectively enforced because it originates from local stakeholders and was approved by park authorities. Many interviewed villagers stated that they are very happy to abide by forest protection measures, acknowledging that they are critical for ensuring a prosperous and sustainable future, and moreover, they are also pleased that there is recognition of their traditions and rules pertaining to forest management and conservation.

The forest is also an important resource for mushroom-foraging. A rich selection of edible mushrooms can be found in the forest, and currently the most renowned and valuable species is the matsutake mushroom (Tricholoma matsutake), which is commercially collected and exported to Japanese markets (He 2010). The Tibetan people in Hongpo Village have been involved in commercial matsutake collection since the late 1990s, before the park was established. Nowadays, commercial matsutake collection accounts for on average $20-30 \%$ of cash income per household. Collection activities take place not only in their collective-owned forest, but also in the state-owned forest, which has historically been managed by local people in accordance to customary rights. These customary rights include clear boundaries between different villages in term of which villages are apportioned which plots of forest land for collection. The village also has local rules to avoid overharvesting and exclude access to outside collectors. After the park was established, the government allowed mushroom-picking activities to commence as before. As stated by the forest officials:

Matsutake picking does impact the forest, but it can
actually also help protect the forest because local people
know that good mushrooms can only grow if there is a
healthy forest ecosystem. Also, local mushroom pickers
can work as unpaid "forest rangers" to assist with fire
control and illegal cutting. (Interviewed in Shangri-La
county, 1 August 2014)

Forest use also has an important spiritual component. In Tibetan Buddhism, the dominant religion in the area, locals believe that the landscape is sacred, particularly certain holy mountains. These holy mountains also function well in conservation schemes, as any cutting or hunting activities are prohibited on their slopes. Each natural village has 4-14 holy mountains associated with it. The holy mountain is the home of the Buddha who protects the village, so locals traditionally hold ritual prayer events at mountain sites twice a month, once in the beginning and once in the middle of the month, in accordance with the lunar calendar. The holy mountain also receives visitors and pilgrims who pray for future blessings during inauspicious occurrences. These praying activities might elevate the fire risk, as the burning of tree leaves and incense occur. The government nevertheless recognizes the significance of the cultural practice and allows locals to carry out their religious activities. To mitigate the negative impact, the government has invested approximately 1000 RMB (about US\$150) at each holy mountain site to build a concrete incense burner with a metal chimney as an anti-fire measure. This has been welcomed by the local people as an additional measure to safeguard the holy mountain. In 2010, this practice was subsequently scaled up across the entire prefecture to convert traditional burners into concrete ones. As an interviewed forest official stated, "Protecting the culture is a way to protect natural resources."

In sum, the government recognizes that the multipurpose nature of the forest also serves ecological, economic, and cultural functions (Fig. 3). Involving local people and respecting their cultural practices are examples in which local CES contribute to meet the twin objectives of conservation and satisfying local cultural needs. This establishes trust and strengthens the relationship between park and people.

Fig. 3. The multifunctionality of forest (A), for fuelwood (B), for commercial non-timber forest products (C), and for religious. needs (D).

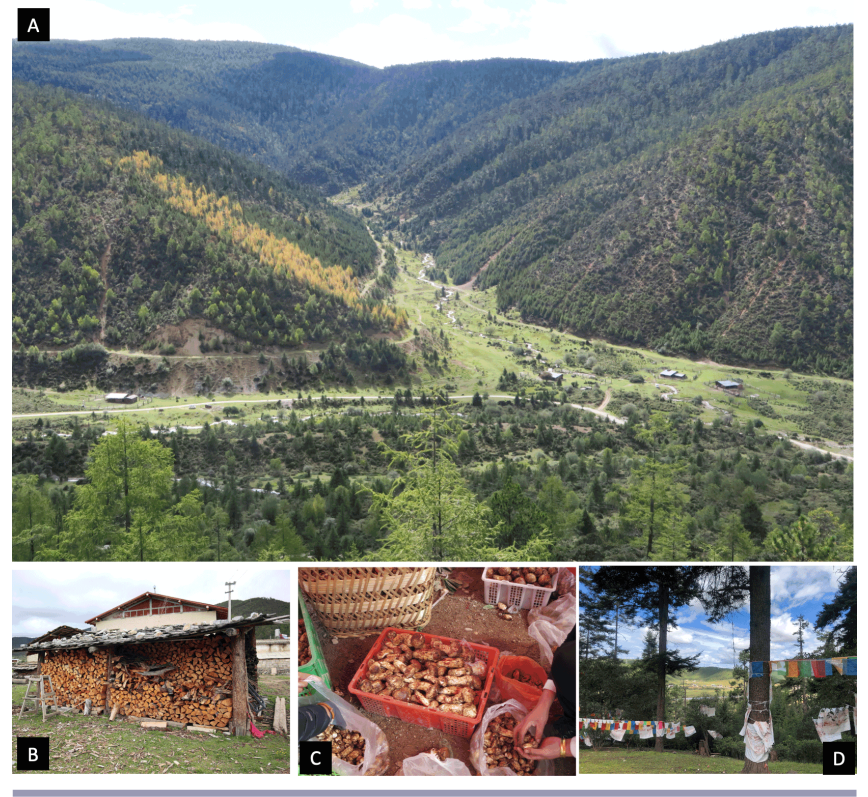

\section{Conserving the sacred waterscape}

Water is a sacred resource for Tibetan people. At home, Tibetans will allocate water storage beside the prayer area of their home. Water taken from their holy mountains also has special uses in morning prayer and other ritual activities. Apart from these, Tibetan people also practice both sky and water burial. Water burial is commonly practiced for ordinary people in the village. Many funerals for villagers are held at the riverside by the village. Rivers, therefore, are imbued with sanctity in Tibetan culture, and other uses of rivers and water are prohibited.

In Pudacuo, the Shudugang River, originating from Shudu Lake in the park, flows through the nearby 15 natural villages. The wellpreserved watershed of the Shudugang River is an important sacred waterscape for each natural village in Hongpo as it functions as a site for practicing water burial. As most villagers mentioned, it is a common practice for people to have the water burial from April to November if people pass away when the water 
has not yet frozen. There is a particular site associated with each village for conducting water burials featuring good tree cover to partially hide the activity (Fig. 4). A shaman from the village will cut the body into small pieces and place them into the water piece by piece. A Lama will conduct the ritual and guide prayer. The tradition has been practiced in this way for centuries. Locals believe that this ritual embodies the life cycle present in nature between life and death. The Shudugang watershed therefore provides critical cultural services to the Hongpo people.

Fig. 4. The sacred waterscape has been conserved for the burial site that is hidden behind the tree cover.

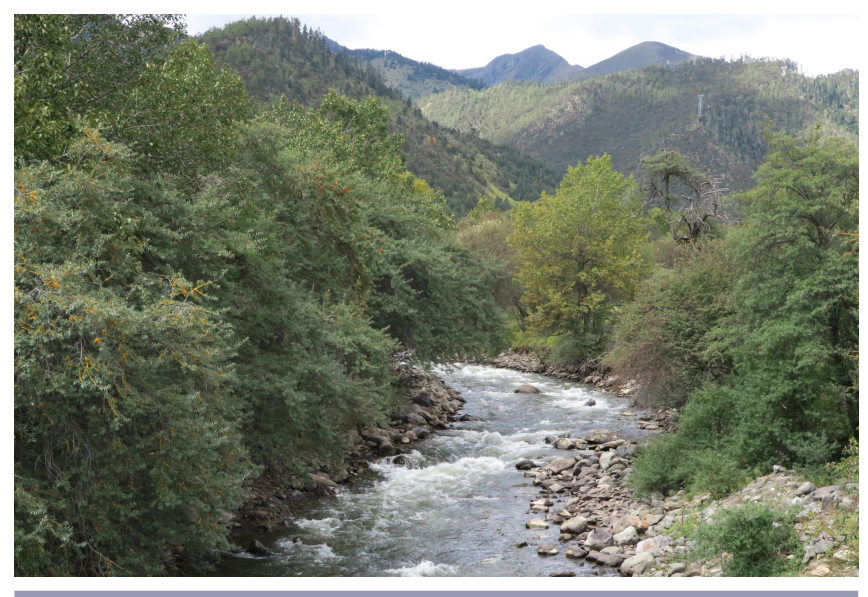

When Pudacuo National Park was established, officials and park managers realized that local practices must be fully respected. In Luorong Natural Village (a natural village of Hongpo Administrative Village), for example, their burial site is close to Shudu Lake, a key tourist attraction encircled by a boardwalk circumnavigated for tourists to enjoy the stunning lakeside landscape. To avoid interrupting local cultural practices, park authorities in consultation with the villagers decided to build the boardwalk far away from the water burial site of Luorong Natural Village. Similar consultations happened in Bengjiading Natural Village (a natural village of Hongpo Administrative Village), when the government attempted to minimize the impact of flood control on their cultural sacred site. One villager from the village stated the following:

\section{The government has always tried to avoid letting their construction and development activities affect our water burial site. Also, they do not make any changes in the landscape or path from our village to the burial site, as this path is also sacred. We feel good that they act like this. (Interviewed in Hongpo Administrative Village, 2 October 2019)}

Interestingly, there has been a water project in Luorong Natural Village that presented difficulties in avoiding the nearby burial site. In 2017, park authorities wished to build a small water supply plant near the burial site of Luorong Natural Village to supply water for park operations as well as drinkable water. The original plan was to build the plant upstream from the burial site, because it would generate clean drinking water. This plan did not receive approval from villagers of Luorong Natural Village, who were concerned that the project would impact the burial site and "pollute" the river, as it would affect the natural upstream flow. The villagers entered into negotiations with the government to move the water supply plant downstream from the burial. The government accepted the request of the villagers but mandates villagers to report funerals, allowing the government to cut the water supply for seven days, letting the body flow downstream and water return to a purified state in order to avoid contamination issues.

To summarize, the government has shown it is more than willing to compromise and adjust its activities when encountering local water-related issues. Given the degree of significance afforded to water and river ways by Tibetan people, these compromises help protect the local cultural landscape and traditions, which contributes to protecting the CES that meet both conservation and cultural needs. These compromises also reinforce the high degree of trust between locals and government officials, allowing for the development of creative solutions and enacting more effective multistakeholder policies toward national park building.

\section{DISCUSSIONS AND CONCLUSION}

Unlike existing research that predominantly focuses on the effectiveness of PAs, this research uses Pudacuo National Park as a case study for examining the practice of CES in the context of designing and planning a national park to understand the relationship between people and parks from a cultural dimension. The paper investigates the processes by which CES were incorporated into conservation efforts along with national park construction. Drawing on the findings of the research, the theoretical and empirical implications lie in key three aspects.

First, this research suggests that CES can be explored through examining the cultural practices of people closely associated with an environment. Cultural practices in a specific locale of the Global South encompass a wide range of livelihood activities, including agriculture, pastoralism, forest management, water use, as well as spiritual and religious activities. As shown in this research, cultural phenomena and ecosystem stewardship practices manifested in local livelihood activities through agropastoralism, utilization of the multifunctionality of forests, and sacred waterscape. These livelihood activities formed local cultural practices closely entwined with ecosystem services, bolstering conservation efficiency and enhancing the design and planning of the national park. Examining CES via local cultural practice extends beyond the existing knowledge of CES in recreational or touristic values as well as in human well-being (de Groot et al. 2010, Bryce et al. 2016, Fish et al. 2016, Stålhammar and Pedersen 2017, Bullock et al. 2018). Understanding how local cultural practices interact with ecosystem services provides a holistic perspective of CES and allows deep engagement with local cultural means (Chan et al. 2012, Gould et al. 2015). Therefore, it can help for not only CES assessment, but more importantly contribute to conservation policy making and practice (Pascua et al. 2017).

Second, the research reveals the significant role of inclusiveness in conservation. Differing from considering poverty reduction and human well-being in conservation, inclusiveness of conversation should be rooted in recognition as a pre-condition for effective conservation (Martin et al. 2016, He et al. 2021). It requires the understanding and consideration of cultural differences, identities, etc., for cultivating sustainable ecosystem 
management schemes (Sikor et al. 2014). As revealed by our case study in Pudacuo, unique Tibet cultural practices for holy mountains and sacred waterscapes have largely been recognized by the government, evident through the behavior of officials who are more than willing to compromise and adjust planning in order to meet local spiritual and religious needs. Moreover, the recognition of customary land tenure arrangements of forest and rangeland supports local agropastoralism practices as well as the multifunctional management of the forest, meeting both local livelihood and cultural needs while implementing meaningful conservation reform. Yet another benefit is that this inclusive approach promotes an aesthetic component of CES, generating tourist opportunities that benefit both the local government and people. This case thus presents a relatively inclusive approach for national park management that can lead to positive outcomes in both conservation and cultural preservation. As Martin et al. (2016) and Sikor et al. (2014) argued, conservation of ecosystems should look beyond a conventional model, with special emphasis giving social recognition to indigenous people, while also carefully pursuing broad inclusiveness among conservation stakeholders.

Third, this research calls for greater attention to non-material benefits from ecosystem services that go beyond aesthetic, recreational, touristic values or monetary calculations (Chan et al. 2012, Gould et al. 2015). Rather, a deep engagement with cultural norms and practices required a contextualized approach to understand the embeddedness of local cultural meanings and needs within the surrounding biophysical ecosystem. This is particularly crucial in the Global South because it is a repository of rich biocultural diversity. As shown in this case study, local cultural practices and meanings infused into holy mountains, sacred waterscapes, and their agropastoralism all reflect aspects of Tibetan religion and spiritual needs, which positively interact with the biophysical ecosystem and are important components of CES. Thus, the valuation of embeddedness of local culture into the surrounding biophysical ecosystem is a way to contextually value CES. Separating ecosystem service assessment from local cultures in conservation practice and focusing on the value of CES from a monetary perspective (recreational or touristic benefits) would lead to negative effects both in conservation and local culture (e.g., Yeh 2013, Zinda 2017).

In conclusion, the positive interactions between CES and conservation shown in this research provide insightful policy implications in three areas. First, current conservation policy for the development of national parks in China and beyond needs to recognize local cultural practices and consider local cultural needs when planning conservation projects. To strengthen the role of CES for conservation, it requires the institutionalization of CES assessment to ensure that the cultural dimension has been appropriately considered for decision making in conservation policy, which is largely ignored under current policies. Second, there is an urgent need for new investments to promote inclusiveness in conservation that would help incorporate CES into conservation planning. This requires a participatory approach for PA-building throughout the whole process, from planning, implementation, to management. The involvement of local people for PA planning and management would contribute to not only conservation and CES but also livelihood development. The development of an inclusive conservation model in China also requires the government to scale up successes from specific cases, which can be accomplished via cross-site visits, opening new channels of communication between actors, and shared documentation. Finally, there is an urgent need for further research on CES to gain a better understanding of the interplay between local cultures and ecosystem service assessment. Further research will require a multidisciplinary team that goes beyond the usually assembled ecologists and economists. Thus, the governments should set up specific central funding schemes to encourage interdisciplinary research in ecosystem service assessment requiring the involvement of social scientists, particularly anthropologists and sociologists, whose skills at generating refined ethnographic data are paramount in closing gaps between divergent stakeholder interests.

${ }^{[1]}$ In accordance with The International Union of Conservation of Nature (IUCN) PAs categories system, PAs in China include nature reserves (strictly for protection), scenic areas (protection and tourism development), and national parks (integrated conservation with education and recreation; see also Zinda 2012).

${ }^{[2]}$ Economically underdeveloped regions include the Southwest, the West, Northwest, and Northeast, where most PAs are allocated.

${ }^{[3]}$ A variety of cash crops have been reported booming in PAs, including maize, potato, cabbage, rubber, sugarcane, and coffee.

${ }^{[4]}$ Pudacuo was widely regarded as the first national park in China when the Yunnan Provincial Government declared its completion in 2007; however, at a national level, the Three-River-Source National Park, founded in 2016, claims the official title.

[5] Administrative village is the lowest administrative body in China and is composed of several natural villages (naturally settled hamlets).

${ }^{[6]}$ Although local people still had access to land after the park was built, their activities were restricted for timber harvest, rangeland management, and using fire, etc.

[7] The results of the multidisciplinary research team had particularly taken local needs and cultural dimension into consideration with extensive involvement of social scientists, i.e., sociologists, anthropologists, and economists.

[8] Households throughout the park have been classified in accordance with three categories for dispensing differentiated rates of compensation: (1) highest-impacted households, whose lands are entirely within the park and whose residents were already engaged in horseback-riding before the park was established; (2) medium-impacted households, whose lands are partially in the park and less engaged in horseback-riding; and (3) low-impacted households, who have only been affected by restriction in access to NTFP and firewood.

Responses to this article can be read online at: https://www.ecologyandsociety.org/issues/responses. php/12572 


\section{Acknowledgments:}

This research financially benefited from National Natural Science Foundation of China (Project No. 72063037), the Ministry of Education of China (Project No. 16JJD850015), and National Social Science Foundation of China (Project No. 20BMZ162). We thank Dr. Pamela McElwee and other guest editors for including this paper in the special feature, Austin G. Smith for Englishlanguage editing, Huafang Chen for mapping, Dr. Hua Yang and Dr. Zhongyun Zhang and local interlocutors for sharing their insights with us. The early version of this paper benefited significantly from anonymous reviewers' constructive comments.

\section{Data Availability:}

The datalcode that support the findings of this study are available on request from the corresponding author.

\section{LITERATURE CITED}

Adams, W. M. 2004. Against extinction: the story of conservation. Earthscan, London, UK. https://doi.org/10.4324/9781849770415

Ahrends, A., P. M. Hollingsworth, A. D. Ziegler, J. M. Fox, H. Chen, Y. Su, and J. Xu. 2015. Current trends of rubber plantation expansion may threaten biodiversity and livelihoods. Global Environmental Change 34:48-58. https://doi.org/10.1016/j. gloenvcha.2015.06.002

Allendorf, T. D., and J. Yang. 2013. The role of ecosystem services in park-people relationships: the case of Gaoligongshan Nature Reserve in Southwest China. Biological Conservation 167:187-193. https://doi.org/10.1016/j.biocon.2013.08.013

Bridgewater, P., and I. D. Rotherham. 2019. A critical perspective on the concept of biocultural diversity and its emerging role in nature and heritage conservation. People and Nature 1 (3):291-304. https://doi.org/10.1002/pan3.10040

Brockington, D., and J. Igoe. 2006. Eviction for conservation: a global overview. Conservation and Society 4:424-470.

Brown, M., and T. Murtha. 2019. Integrating natural and cultural resources in North American large-landscape conservation. Environmental Practice 21(2):57-68. https://doi.org/10.1080/146$\underline{60466.2019 .1601935}$

Bryan, B. A., L. Gao, Y. Ye, X. Sun, J. D. Connor, N. D. Crossman, M. Stafford-Smith, J. Wu, C. He, D. Yu, et al. 2018. China's response to a national land-system sustainability emergency. Nature 559:193-204. https://doi.org/10.1038/s41586-018-0280-2

Bryce, R., K. N. Irvine, A. Church, R. Fish, S. Ranger, and J. O. Kenter. 2016. Subjective well-being indicators for large-scale assessment of cultural ecosystem services. Ecosystem Services 21:258-269. https://doi.org/10.1016/j.ecoser.2016.07.015

Bullock, C., D. Joyce, and M. Collier. 2018. An exploration of the relationships between cultural ecosystem services, sociocultural values and well-being. Ecosystem Services 31:142-152. https://doi.org/10.1016/j.ecoser.2018.02.020
Chan, K. M., A. D. Guerry, P. Balvanera, S. Klain, T. Satterfield, X. Basurto, X. Basurto, A. Bostrom, R. Chuenpagdee, R. Gould, B. S. Halpern, N. Hannahs, J. Levine, B. Norton, M. Ruckelshaus, R. Russell, J. Tam, and U. Woodside. 2012. Where are cultural and social in ecosystem services? A framework for constructive engagement. BioScience 62(8):744-756. https://doi.org/10.1525/ bio.2012.62.8.7

Chen, H., Z.-F. Yi, D. Schmidt-Vogt, A. Ahrends, P. Beckschäfer, C. Kleinn, S. Ranjitkar, and J. Xu. 2016. Pushing the limits: the pattern and dynamics of rubber monoculture expansion in Xishuangbanna, SW China. PLoS ONE 11(2):e0150062. https:// doi.org/10.1371/journal.pone.0150062

Chen, S., Z.-F. Yi, A. Campos-Arceiz, M.-Y. Chen, and E. L. Webb. 2013. Developing a spatially-explicit, sustainable and riskbased insurance scheme to mitigate human-wildlife conflict. Biological Conservation 168:31-39. https://doi.org/10.1016/j. biocon.2013.09.017

Cuerrier, A., N. J. Turner, T. C.Gomes, A. Garibaldi, and A. Downing. 2015. Cultural keystone places: conservation and restoration in cultural landscapes. Journal of Ethnobiology 35 (3):427-449. https://doi.org/10.2993/0278-0771-35.3.427

Daniel, T. C., A. Muhar, A. Arnberger, O. Aznar, J. W. Boyd, K. M. Chan, R. Costanza, T. Elmqvist, C. G. Flint, P. H. Gobster, et al. 2012. Contributions of cultural services to the ecosystem services agenda. Proceedings of the National Academy of Sciences 109(23):8812-8819. https://doi.org/10.1073/pnas.1114773109

De Groot, R. S., R. Alkemade, L. Braat, L. Hein, and L. Willemen. 2010. Challenges in integrating the concept of ecosystem services and values in landscape planning, management and decision making. Ecological Complexity 7:260-272. https://doi.org/10.1016/ j.ecocom.2009.10.006

Dowie, M. 2011. Conservation refugees: the hundred-year conflict between global conservation and native peoples. MIT Press, Cambridge, Massachusetts, USA. https://doi.org/10.7551/ mitpress/7532.001.0001

Fish, R., A. Church, and M. Winter. 2016. Conceptualising cultural ecosystem services: a novel framework for research and critical engagement. Ecosystem Services 21:208-217. https://doi. org/10.1016/j.ecoser.2016.09.002

Fisher, J. A., H. Dhungana, J. Duffy, J. He, M. Inturias, I. Lehmann, A. Martin, D. M. Mwayafu, I. Rodríguez, and H. Schneider. 2020. Conservationists' perspectives on poverty: an empirical study. People and Nature 2:678-692. https://doi. org/10.1002/pan3.10098

Garibaldi, A., and N. Turner. 2004. Cultural keystone species: implications for ecological conservation and restoration. Ecology and Society 9(3):1. https://doi.org/10.5751/ES-00669-090301

Gould, R. K., S. C. Klain, N. M. Ardoin, T. Satterfield, U. Woodside, N. Hannahs, G. C. Daily, and K. M. Chan. 2015. A protocol for eliciting nonmaterial values through a cultural ecosystem services frame. Conservation Biology 29(2):575-586. https://doi.org/10.1111/cobi.12407

He, G., X. Chen, S. Beaer, M. Colunga, A. Mertig, L. An, S. Zhou, M. Linderman, Z. Ouyang, S. Gage, S. Li, and J. Liu. 2009. Spatial 
and temporal patterns of fuelwood collection in Wolong Nature Reserve: implications for panda conservation. Landscape and Urban Planning 92(1):1-9. https://doi.org/10.1016/j. landurbplan.2009.01.010

He, J. 2010. Globalised forest-products: commodification of the matsutake mushroom in Tibetan villages, Yunnan, Southwest China. International Forestry Review 12(1):27-37. https://doi. org/10.1505/ifor.12.1.27

He, J. 2018. Harvest and trade of caterpillar mushroom (Ophiocordyceps sinensis) and the implications for sustainable use in the Tibet region of Southwest China. Journal of Ethnopharmacology 221:86-90. https://doi.org/10.1016/j.jep.2018.04.022

He, J. 2020. Situated payments for ecosystem services: local agencies in the implementation of the sloping land conversion programme in Southwest China. Development and Change 51 (1):73-93. https://doi.org/10.1111/dech.12539

He, J. 2021. Institutional bricolage in payment for ecosystem services: insights from the Sloping Land Conversion Programme in upland communities, Southwest China. Asia Pacific Viewpoint https://doi.org/10.1111/apv.12298

He, J., A. Martin, R. Lang, N. Gross-Camp. 2021. Explaining success on community forestry through a lens of environmental justice: local justice norms and practice in China. World Development 142:105450. https://doi.org/10.1016/j.worlddev.2021.105450

Hirons, M., C. Comberti, and R. Dunford. 2016. Valuing cultural ecosystem services. Annual Review of Environment and Resources 41:545-574. https://doi.org/10.1146/annurevenviron-110615-085831

Holmes, G., C. Sandbrook, and J. A. Fisher. 2017. Understanding conservationists' perspectives on the new-conservation debate. Conservation Biology 31(2):353-363. https://doi.org/10.1111/ cobi. 12811

Huang, Y., J. Fu, W. Wang, and J. Li. 2019. Development of China's nature reserves over the past 60 years: an overview. Land Use Policy 80:224-232. https://doi.org/10.1016/j.landusepol.2018.10.020

Lepofsky, D., C. G. Armstrong, S. Greening, J. Jackley, J. Carpenter, B. Guernsey, D. Mathews, and N. J. Turner. 2017. Historical ecology of cultural keystone places of the Northwest Coast. American Anthropologist 119(3):448-463. https://doi. org/10.1111/aman.12893

Li, W., P. Liu, X. Guo, L. Wang, Q. Wang, Y. Yu, Y. Dai, L. Li, and L. Zhang. 2018. Human-elephant conflict in Xishuangbanna Prefecture, China: distribution, diffusion, and mitigation. Global Ecology and Conservation 16:e0462. https://doi.org/10.1016/j. gecco.2018.e00462

Liu, J., M. Linderman, Z. Ouyang, L. An, J. Yang, and H. Zhang. 2001. Ecological degradation in protected areas: the case of Wolong Nature Reserve for giant pandas. Science 292 (5514):98-101. https://doi.org/10.1126/science.1058104

Martin, A., B. Coolsaet, E. Corbera, N. M. Dawson, J. A. Fraser, I. Lehmann, and I. Rodriguez. 2016. Justice and conservation: the need to incorporate recognition. Biological Conservation 197:254-261. https://doi.org/10.1016/j.biocon.2016.03.021
Martin, A., R. Myers, and N. M. Dawson. 2018. The park is ruining our livelihoods. We support the park! Unravelling the paradox of attitudes to protected areas. Human Ecology 46 (1):93-105. https://doi.org/10.1007/s10745-017-9941-2

Milcu, A. I., J. Hanspach, D. Abson, and J. Fischer. 2013. Cultural ecosystem services: a literature review and prospects for future research. Ecology and Society 18(3):44. https://doi.org/10.5751/ ES-05790-180344

Ministry of Ecology and Environment (MEE). 2018. State of environment in China. China Environment Publishing House, Beijing, China.

Ouyang, Z., H. Zheng, Y. Xiao, S. Polasky, J. Liu, W. Xu, Q. Wang, L. Zhang, Y. Xiao, E. Rao, et al. 2016. Improvements in ecosystem services from investments in natural capital. Science 352 (6292):1455-1459. https://doi.org/10.1126/science.aaf2295

Pascua, P., H. McMillen, T. Ticktin, M. Vaughan, and K. B. Winter. 2017. Beyond services: a process and framework to incorporate cultural, genealogical, place-based, and indigenous relationships in ecosystem service assessments. Ecosystem Services 26:465-475. https://doi.org/10.1016/j.ecoser.2017.03.012

Pudacuo National Park Plan (PNPP). 2009. Pudacuo National Park Plan. Government document (in Chinese). Government of China, Beijing, China.

Sikor, T., A. Martin, J. Fisher, and J. He. 2014. Toward an empirical analysis of justice in ecosystem governance. Conservation Letters 7(6):524-532. https://doi.org/10.1111/ conl.12142

Stålhammar, S., and E. Pedersen. 2017. Recreational cultural ecosystem services: How do people describe the value? Ecosystem Services 26:1-9. https://doi.org/10.1016/j.ecoser.2017.05.010

State Council. 2017. Overall plan for establishing national parks. [Title translated from the Chinese.] Government of China, Beijing, China.

Wang, J.-H. Z. 2019. National parks in China: parks for people or for the nation? Land Use Policy 81:825-833. https://doi. org/10.1016/j.landusepol.2018.10.034

Weckerle, C. S., Y. Yang, F. K. Huber, and Q. Li. 2010. People, money, and protected areas: the collection of the caterpillar mushroom Ophiocordyceps sinensis in the Baima Xueshan Nature Reserve, Southwest China. Biodiversity and Conservation 19 (9):2685-2698. https://doi.org/10.1007/s10531-010-9867-0

Woodhouse, E., P. McGowan, and E. J. Milner-Gulland. 2014. Fungal gold and firewood on the Tibetan plateau: examining access to diverse ecosystem provisioning services within a rural community. Oryx 48(1):30-38. https://doi.org/10.1017/S0030605312001330

Woods, K. M. 2019. Green territoriality: conservation as state territorialization in a resource frontier. Human Ecology 47 (2):217-232. https://doi.org/10.1007/s10745-019-0063-X

Xu, J., L. Chen, Y. Lu, and B. Fu. 2006. Local people's perceptions as decision support for protected area management in Wolong Biosphere Reserve, China. Journal of Environmental Management 78(4):362-372. https://doi.org/10.1016/j.jenvman.2005.05.003 
Xu, J., and D. R. Melick. 2007. Rethinking the effectiveness of public protected areas in southwestern China. Conservation Biology 21(2):318-328. https://doi.org/10.1111/j.1523-1739.2006.00636. $\underline{x}$

Xu, W., Y. Xiao, J. Zhang, W. Yang, L. Zhang, V. Hull, Z. Wang, H. Zheng, J. Liu, S. Polasky, L. Jiang, Y. Xiao, X. Shi, E. Rao, F. Lu, X. Wang, G. C. Daily, and Z. Ouyang. 2017. Strengthening protected areas for biodiversity and ecosystem services in China. Proceedings of the National Academy of Sciences 114 (7):1601-1606. https://doi.org/10.1073/pnas.1620503114

Xu, W. H., S. L. Pimm, A. Du, Y. Su, X. Fan, L. An, J. G. Liu, and Z. Ouyang. 2019. Transforming protected area management in China. Trends in Ecology and Evolution 34:762-766. https:// doi.org/10.1016/j.tree.2019.05.009

Yeh, E. T. 2013. The politics of conservation in contemporary rural China. Journal of Peasant Studies 40(6):1165-1188. https:// doi.org/10.1080/03066150.2013.859575

Zang, Z., X. Zou, P. Zuo, Q. Song, C. Wang, and J. Wang. 2017. Impact of landscape patterns on ecological vulnerability and ecosystem service values: an empirical analysis of Yancheng Nature Reserve in China. Ecological Indicators 72:142-152. https://doi.org/10.1016/j.ecolind.2016.08.019

Zhang, Z., D. Zhang, N. Wang, A. Du, L. Kong, W. Xu, Z. Ouyang. 2020. Experience, achievement, problems, and recommendation of the first batch of China's nation park system pilots. [Title translated from the Chinese.] Acta Ecologica Sionica 40(24):8839-8850.

Zhou, D. Q., and R. E. Grumbine. 2011. National parks in China: experiments with protecting nature and human livelihoods in Yunnan province, Peoples' Republic of China (PRC). Biological Conservation 144(5):1314-1321. https://doi.org/10.1016/j.

biocon.2011.01.002

Zhu, H., Z. F. Xu, H. Wang, and B. G. Li. 2004. Tropical rain forest fragmentation and its ecological and species diversity changes in southern Yunnan. Biodiversity \& Conservation 13 (7):1355-1372. https://doi.org/10.1023/B:BIOC.0000019397.98407. $\underline{\mathrm{c} 3}$

Zinda, J. A. 2012. Hazards of collaboration: local state cooptation of a new protected-area model in southwest China. Society \& Natural Resources 25(4):384-399. https://doi. org/10.1080/08941920.2011.557826

Zinda, J. A. 2017. Tourism dynamos: selective commodification and developmental conservation in China's protected areas. Geoforum 78:141-152. https://doi.org/10.1016/j.geoforum.2015.08.004 